\title{
Performance evaluation model of university student organization based on Data Envelopment Analysis
}

\author{
Hongqing Liu \\ Hunan vocational college of modern logistics, Changsha, Hunan,410131
}

\begin{abstract}
Keywords: Higher vocational colleges, Innovation and entrepreneurship education, Data envelopment analysis, Quality evaluation.
\end{abstract}

\begin{abstract}
Taking the power source in the social entrepreneurship theory framework as the basic principle, from the two aspects of the input and output of innovation and entrepreneurship education in higher vocational colleges, the design and research of quality evaluation indicators are carried out. The case investigation of a national key universities in Guangdong Province, through data envelopment analysis (DEA), found that the quality evaluation of higher vocational education innovation must be the goal and mission of education outstanding achievement higher vocational education innovation should keep the humanities and social science will serve the adaptive advantage in service, but also to enhance science and technology specialty the innovation and entrepreneurship education quality, especially to strengthen the transformation of achievements in scientific research and market development ability.
\end{abstract}

\section{Introduction}

In the field of education, innovation and entrepreneurship education has also received widespread attention from educational researchers and practitioners. However, in order to ensure the achievement of innovation and entrepreneurship education, continuous evaluation and systematic improvement of [1] must be carried out. Quality assessment has become an important content to ensure the scientific and standardized implementation process of innovation and entrepreneurship education, and to promote the quality of education. There are many researches on innovation and entrepreneurship education system in China, but there are few researches on quality evaluation. On the basis of social entrepreneurship quality evaluation theory based on the foreign "third sector", by DEA (Data Envelopment Analysis) to study the quality evaluation of higher vocational education innovation process model, rich theory of innovation and entrepreneurship education quality evaluation in order to explore the practical application value at the same time.

\section{The theoretical basis of quality evaluation of innovation and Entrepreneurship Education}

There are two main ideas for the quality evaluation of innovation and Entrepreneurship Education: one is to evaluate the satisfaction degree of stakeholders from innovation and entrepreneurship education. The developed countries in the field of higher education stakeholders satisfaction research is relatively mature, in the process of education stakeholders -- students, parents, business partners, investors, including government agencies are included in the satisfaction evaluation system. Because satisfaction can directly show the customer evaluation part of innovation and entrepreneurship education, it has the objective and direct characteristics, but the evaluation methods are subjective, and the content orientation is relatively single [2]. Another way of thinking is to learn from the trusted third party evaluation. In 2008 the EU launched a for six dimensions of strategy, innovation and entrepreneurship education organization system, teaching and learning, extension activities, development, innovation and entrepreneurship education resources as the main content of the EU on innovation and entrepreneurship education survey, 
provides detailed data of [3] innovation and entrepreneurship education present situation of the development of European higher Education under the. Domestic researchers also combined with the actual development of higher vocational colleges are a lot of research on [4], some scholars try using AHP and Fuzzy AHP in Higher Vocational Colleges entrepreneurship education evaluation system research and design. These studies have reached a consistent conclusion in the evaluation of innovative entrepreneurship education courses, teachers, practice conditions, external environment and innovation and entrepreneurship results.

In recent years, social entrepreneurship (social entrepreneurship, also known as social enterprises or entrepreneurship, referred to as se, has become the focus of the development direction of entrepreneurship research is also beginning to be applied in innovation and entrepreneurship education and social entrepreneurship theory and evaluation of relevant evaluation methods. Social entrepreneurship needs of the society, with the social concern and development, enrich the content and form of entrepreneurial activities, social entrepreneurship refers to a specific economic or social goals, rather than to maximize profits for the main pursuit of public interests and business activities, and help to solve the problem of unemployment and social exclusion that helps to ease the social contradictions and social management innovation. Social entrepreneurship not only focuses on the creation of economic value, but also pays more attention to the realization of social value or social impact, thus highlighting the "dual value goal"'. Innovation and entrepreneurship education and knowledge creation and inheritance of academic innovation of science and technology, social services, combined with the promotion of economic development, social influence also focus on the social value of education and entrepreneurial talent training, public welfare. Therefore, in essence, the innovation and entrepreneurship education in Colleges and universities is the public welfare oriented education, and has the typical characteristics of social entrepreneurship.

Innovation and entrepreneurship education quality evaluation is essentially to meet the needs of the society for innovation and entrepreneurship, the input of resources, to achieve entrepreneurial achievements, and the achievements and social impact assessment work, from this perspective, is widely used in the field of social entrepreneurship source logic theoretical basis for quality assessment of Higher Vocational Education Innovation has the same application of.

\section{Construction of quality evaluation system and method selection}

\subsection{Quality evaluation research design ideas}

The quality evaluation of social entrepreneurship in foreign countries is based on the theory of power source (input output effect influence) [11], focusing on the comparison and analysis between input and output. Using the quality evaluation model and method of foreign social entrepreneurship and the innovation and entrepreneurship education of Higher Vocational Colleges in China is the primary problem to be solved in the quality evaluation process. Starting from the basic principle of the logic flow of social entrepreneurship power source, this paper studies and designs the two aspects of input and output of innovation and entrepreneurship education, as shown in figure 1 . In particular, we need to consider how to use measurable indicators, such as, innovation, entrepreneurship education talent training or reform what is the mission? What is the strategic goal of innovation and entrepreneurship education? Can mission or strategic goals be achieved? How much is the social impact of entrepreneurship education? Wait According to the expert interview and the innovation of Higher Vocational Colleges entrepreneurship education in the actual situation, the complete list of possible factors that affect the quality of innovation and entrepreneurship education, and then through the Social Entrepreneurship BSc makes the interview data been divided into key indicators.

Follow, concise and operational principle of the system construction of quality evaluation index system, the selection of curriculum resources (A1) and extension activities (A2), teaching force (A3) and system environment (A4) into four factors as quality evaluation, specifically refers to the amount of information innovation and entrepreneurship education input of manpower and the 
Treasury, materials and information resources; at the same time, the choice of teaching effect (B1), (B2), the results of entrepreneurship Awards (B3) and social influence (B4) as output factors of quality assessment, specifically refers to the number of measurable results of innovation entrepreneurship education information. Each factor is composed of a number of quantitative key evaluation indicators, as shown in table 1.

\subsection{Principles and methods of DEA Analysis}

(data envelopment analysis, also called DEA model) is an assessment of the U.S. operations researcher Charnes proposed multi input and multi output decision makingunit (decision making unit DMU) the relative effectiveness evaluation method and system analysis method [12]. Because the DEA analysis does not need a unified index unit, the subjective preference of the index weight determination process is avoided. Therefore, the DEA method has great advantages in simplifying the algorithm and avoiding errors as far as possible, especially for the evaluation of the units of the same nature.

Charnes et al. (1978) first gave the C2R model, and banker et al. (1984) proposed the BC2 model to judge the effectiveness of DMU technology. Overall, represented by C2R model type assumption returns to scale for the proportion of such changes, suitable for DMU ideal operation type, represented by BC2 model is the assumption that the changes of input and return both non proportional, thus more in line with the research of complex changes under [13]. The higher occupation colleges entrepreneurship education because education concept, personnel structure, resource changes and other factors, such as changes in non existing investment and the profit ratio of quality, therefore this research chooses BC2 model to evaluate the innovation and entrepreneurship education. (three) data acquisition and statistical methods

According to the construction quality evaluation system, statistics, teaching and management data and social impact data of 14 departments of a national key higher vocational college in Guangdong province and their supporting materials are given. The school has a wide range of disciplines, innovation and entrepreneurship education system is complete, covering all the professional students, and entrepreneurial students fruitful results, more representative in Higher Vocational colleges. In order to avoid the time delay characteristics of entrepreneurial activities, the arithmetic average value of 2011-2015 years data was calculated, and the data were analyzed by maxdea6.0 software package.

\section{Data analysis results}

According to the concept of BC2 model, theta value (optimal solution) is 1, representing the relatively high efficiency, such as slack variables and were 0 , the corresponding DMU completely effective; if the theta value is equal to 1 , and the slack variable is not equal to 0 , then the corresponding DMU is effective if the input and output unit, and a not for 0 , for the weak effective unit; the rest of the results of input and output unit is invalid. Each professional as a decision-making unit, data analysis is as follows:

From the results, 14 majors, 4 professional (accounting, project cost, communication engineering and senior nursing) of relatively low efficiency, invalid input and output unit, 10 departments or professional efficient or weakly efficient unit, see table 2. Specifically, e-commerce, business management, art design and software development are completely effective input output units, that is, in all professions, the above 4 professional inputs get the best income. Secretarial, business English and mechanical and electrical engineering are effective input output units, and the gains are better. Early childhood education, legal affairs and architectural design are weak effective units, and the efficiency is low.

In addition, this study also found that compared with the humanities, the innovation and entrepreneurship education of science and engineering disciplines has lower input-output efficiency. With communication engineering and advanced care, for example, the results of the two colleges in s+2 were 0.29 and 0.27 respectively, showing that there were $29 \%$ and $27 \%$ gaps in entrepreneurial 
outcomes compared with other professionals in the forefront of efficiency. From the input-output comparison, inefficient or inefficient output is mainly reflected in the entrepreneurial achievements, awards results and social impact.

\section{Discussion and conclusion}

\subsection{Integration of social entrepreneurship theory and quality evaluation of innovation and Entrepreneurship Education}

From the results of empirical research, the theory and method of social entrepreneurship and innovation of Higher Vocational entrepreneurship education has a high degree of integration, the exploration of a new theoretical basis for the quality assessment of innovation and entrepreneurship education, entrepreneurship and the young "exotic" in China in the context of social development to find the extension and innovation in the field of education. Based on this, the quality assessment of innovation and entrepreneurship education in higher vocational colleges can be combined with social entrepreneurship theory, while highlighting the following ideas: first, quality evaluation should not only focus on the education process itself, but also to the mission and strategic objectives focus on innovation and entrepreneurship education completion, different mission and purpose have different input and expected output. Second, innovation and entrepreneurship education output both the teaching effect and the dominant factors such as the award-winning achievements also contain hidden factors, such social value and social influence, the results can also be combined with the relevant methods of social entrepreneurship theory, qualitative research will gradually turn to the original fuzzy quantitative research and comparative measurable.

\subsection{Quality evaluation results and causes of innovation and entrepreneurship education in Higher Vocational Colleges}

The quality of innovation and entrepreneurship education evaluation has higher vocational assessment by the traditional scale is gradually turning to the details of the deep evaluation, with an evaluation index system for different needs and levels of entrepreneurship education is not realistic. Therefore, it is of great value to use the DEA analysis method to evaluate the input output comparison of different units of the same type. This study aimed at professional vocational colleges or departments of the DEA analysis to identify effective and invalid actual input and output ratio, different teaching units of entrepreneurship education quality provides objective reference. The humanities and social science majors in science generally high efficiency of input and output, reflects the actual situation of innovation and entrepreneurship education in higher vocational colleges. On the one hand, innovation and entrepreneurship education and professional education has better integration, most teaching units only through open one or two door general courses to promote innovation and entrepreneurship education, it is difficult to make the students' professional skills will be flexibly applied to the field of innovation and entrepreneurship. On the other hand, higher vocational colleges professional setting close to the needs of local economic development, business management, art design and other professional activities has inherent advantages in innovation and entrepreneurship education, entrepreneurship and innovation for the professional personnel training work combined. The development of software technology, electronic commerce and Internet technology is closely linked to the discipline in innovation and entrepreneurship education also showed the advantages of high efficiency, but the traditional science and engineering, there is still a gap in terms of philosophy, education and employment of teachers, integration of resources and innovative achievements cultivating, innovation and Entrepreneurship education has not received due attention.

According to the above analysis, the innovation and entrepreneurship education in higher vocational colleges should keep the advantages of Humanities and social science majors, and improve the quality of innovation and entrepreneurship education of traditional science and engineering majors. In the transformation of students' employment concept, innovative teacher 
training, commercial transformation of scientific research results and social resources integration to increase support. At the same time, the establishment of innovative entrepreneurship education and professional education in the depth of the integration of the "endogenous" idea of talent cultivation, not only focus on innovation and entrepreneurship education scale, but pay more attention to the deep needs of students, to establish a clear hierarchy of innovation and entrepreneurship education mechanism.

\section{References}

[1]Sennifer W. Chan, Yingyue Zhang, and Kathryn E. Uhrich, Amphiphilic Macromolecule Self-Assembled Monolayers Suppress Smooth Muscle Cell Proliferation, Bioconjugate Chemistry, 2015, 26(7), 1359-1369.

[2]Yingyue Zhang, Evan Mintzer, and Kathryn E. Uhrich, Synthesis and Characterization of PEGylated Bolaamphiphiles with Enhanced Retention in Liposomes, Journal of Colloid and Interface Science, 2016, 482, 19-26.

[3]Yingyue Zhang, Ammar Algburi, Ning Wang, Vladyslav Kholodovych, Drym O. Oh, Michael Chikindas, and Kathryn E. Uhrich, Self-assembled Cationic Amphiphiles as Antimicrobial Peptides Mimics: Role of Hydrophobicity, Linkage Type, and Assembly State, Nanomedicine: Nanotechnology, Biology and Medicine, 2017, 13(2), 343-352. 